Version accepted for publication

Boud, D., Lawson, R. and Thompson, D. (2013). Does student engagement in self-assessment calibrate their judgement over time? Assessment and Evaluation in Higher Education, 38, 8, 941-956

\title{
Does student engagement in self-assessment calibrate their judgement over time?
}

David Boud

Faculty of Arts and Social Sciences

University of Technology, Sydney, Australia

david.boud@uts.edu.au

Romy Lawson

Faculty of Law, Business and Creative Arts

James Cook University, Australia

romy.lawson@jcu.edu.au

Darrall Thompson

Faculty of Design, Architecture and Building

University of Technology, Sydney, Australia

darrall.thompson@uts.edu.au

Corresponding author: David Boud, Faculty of Arts and Social Sciences

University of Technology, Sydney, PO Box 123, Broadway, NSW 2007, Australia

\begin{abstract}
One of the implicit aims of higher education is to enable students to become better judges of their own work. This paper examines whether students who voluntarily engage in selfassessment improve in their capacity to make those judgements. The study utilizes data from a web-based marking system that provides students with the opportunity to assess themselves on each criterion for each assessment task throughout a program of study. Student marks were compared with those from tutors to plot changes over time. The findings suggest that overall students' judgements do converge with those of tutors, but that there is considerable variation across achievement levels, with weaker students showing little improvement. While the study is limited by the exigencies of voluntary participation and thus consequential gaps in the data set, it shows how judgement over time can be demonstrated and points to the potential for more systematic interventions to improve students' judgements. It also illustrates the use of the web-based marking and feedback software (ReView) that has considerable utility in aiding self-assessment research.
\end{abstract}




\section{Keywords}

Self-assessment, judgement, student participation, learning, assessment software

\section{Introduction}

One of the core purposes of education is to develop the capacity for students to make judgements about their own work (Boud and Falchikov, 2007). Such self-evaluation is needed both to enable effective study, so that students can focus on the most important aspects of their work they need to improve, and to build the skills that they will need in any area of work following graduation. If a graduate is not able to make their own judgements about the quality of their work, they will be ill equipped for most professional or even non-professional roles. The development of the capacity to make self-judgements about performance tends to be an assumed outcome of higher education. That is, it is taken to be part of any course without the need for specific practice. This is possibly an act of faith, as it is rarely evident in curricula through learning activities or assessment processes (O'Donovan, Price \& Rust, 2008).

In contrast to this, research on student self-assessment has suggested that explicit opportunities need to be included for the skill of self-assessing to be developed (eg. Boud, 1995). Building the capacity to make judgements needs to be an overt part of any curriculum and one that needs to be fostered (Boud and Falchikov, 2007). If this is the case, then the following questions arise: How might such capacity for judgement be encouraged? And, does engagement in making such judgements over time improve capacity for doing so? The extensive literature on self-assessment in higher education addresses the first of these questions and suggests that self-assessment activities are beneficial. It has been known for many years that under appropriate conditions students can judge their performance on common assessment tasks (Boud and Falchikov, 1989, Dochy, Segers and Sluijsmans, 1999). Additionally, students in later years of their course are better able to judge their performance than in earlier years (Falchikov and Boud 1989). What is less apparent is students' performance in criteria-based assessment contexts and the circumstances in which their judgement can improve (Ward, Gruppen and Regehr, 2002, Galbraith, Hawkins and Holmboe, 2008).

This paper addresses the second of these questions to determine if more extensive opportunities than are offered by the typical within-module self assessment intervention leads to students improving their capacity to make judgements about their own work. The study uses data from a web-based assessment system that enabled students to make selfassessments against descriptive assessment criteria. It examines the development of student judgement across course modules to explore whether students' judgements improve over time, and whether any effects, in terms of students' grades, differ across a 
cohort.

Data from an online marking system was gathered as a result of student's voluntary use of self-assessment. Students allocated criteria-based grades to their submitted work prior to knowledge of the criteria-based grades they were given by tutors. Lecturers or tutors graded on the same scales without knowledge of the student's judgement. This data enabled us to track students in their self-assessment performance across subjects (units of study/courses) and across semesters. The data provided an opportunistic experiment (as it was not originally collected for this purpose) to study the disaggregated grade judgements of tutors and students across a range of subjects and semesters of study. As students were neither required to self-assess, nor were they rewarded for doing so, there are some data gaps that will be discussed.

\section{Conceptual background}

\section{Developing judgement and how courses limit it}

Graduates who are able to be effective practitioners in any area need to have the capacity to make judgements about their own work. Once students move beyond the protected environment of a course, they need to be able to do this for themselves, in conjunction with others; drawing upon whatever resources they have available to them. A person who has the capacity to make good judgements about their work will be able to know why and how their work can be improved (Black \& Wiliam, 1998). They will also be aware of the scope of their practice and when they will need to refer to and involve others, as well as recognizing areas for further development.

The capacity to make judgements is not well represented in many current assessment practices. Assessment items are often strongly knowledge-based, with criteria unilaterally set by teachers. The role of students tends to be to offer themselves to be assessed by others. This can create dependency on the authority of the teacher, rather than other sources of judgement, and can give rise to the implication that judgements are necessarily made by others. This is in contrast to the self being positioned as an active agent in assessment decisions, as is advocated by many assessment theorists (eg. Nicol and Macfarlane-Dick, 2006, Nicol, 2009).

The making of judgements is often an informal and personal act that may or may not occur as students prepare themselves to be assessed by others. Many formal acts of assessment, particularly those used for summative purposes, are positioned to effectively deny the possibility of students taking such responsibility.

\section{Development over time}

Developing judgement involves more than making self-assessments and it is not 
necessarily strongly promoted by the addition of simple self-assessment interventions (eg. Boud, 1995). It certainly involves more than self-testing. Engagement with criteria and the standards to which they are to be applied is quite central to judgement. Sadler argues that self-evaluative skills need to be developed 'by providing direct authentic evaluative experience for students' (Sadler, 1989, p.119). That is, making specific judgements about particular work.

It is unlikely that one-off examples of self-assessment will build capacity for judgement, and it is even more unlikely that such examples are able to do so beyond the immediate knowledge domain of the particular case. Such capacity needs to be promoted systematically throughout courses, as it is reasonable to assume that, like any expertise, it is related to each knowledge domain encountered (eg. Dreyfus and Dreyfus, 2005).

We assume that the key feature of the development of judgement, like any other kind of expertise, is that it requires consistent engagement over time (eg. Ericsson, Krampe and Tesch-Romer, 1993). Standards for the quality of work need to be assessed and interpreted, and these need to be applied in the work of the student. Different standards for different kinds of work are needed and students need considerable practice in working out how to identify what is appropriate in any given situation and how they can see their own work with sufficient distance to be able to apply such standards.

\section{Calibrating judgement and the role of feedback}

What is required for students to learn how to make judgements? Sadler suggests that students develop skills in evaluating the quality of their own work through moving beyond 'teacher-supplied feedback to learner self-monitoring' and that the instructional system in which they operate [the course] needs to 'make explicit provision for students themselves to acquire evaluative expertise' (Sadler, 1989, p. 143). We posit that students learn by consistently making evaluations and relating these to the evaluations of others: reflecting if their judgements were accurate or not, looking for reasons behind poor judgements and for ways to improve future judgements, wondering what they have missed in making their judgements that others have seen. Such activities cannot be done in isolation. It needs the development of evaluative expertise and the input of others. In particular, it needs input from those who can tell if appropriate judgements about the quality of work are being made. These may be teachers, practitioners, or, for some aspects, students' peers. As Sadler (1989) describes, 'providing guided but direct and authentic evaluative experience for students enables them to develop their evaluative knowledge, thereby bringing them within the guild of people who are able to determine quality using multiple criteria'. (Sadler, 1989: 135).

However, Sadler, following Ramprasad (1983), identified that the possession of 
evaluative expertise is a necessary (but not sufficient) condition for improvement. He identified three conditions for effective feedback: (1) a knowledge of the standards; (2) having to compare those standards to one's own work; and (3) taking action to close the gap between the two (Sadler, 1989: 138). None of these are simple processes. Knowledge of standards requires information about what counts as good work in any particular area and the identification of appropriate criteria that indicate these standards. Comparing these standards to one's own work needs the ability to operationalize or ground the standards in relation to the particular kind of product being judged. This might require the use of models or exemplars of what a standard might mean. Finally, taking action to close the gap requires opportunities for such an activity to reoccur. When courses are forever moving on to new material, occasions for continuing practice might be difficult to find.

What might also be needed to aid comparisons is for judgements to be calibrated against those who might be regarded as experienced judges of the kind of work being considered. Judgements need to be made in the light of those of appropriate others, information gained about discrepancies between the judgement of the novice and that of the experienced judges, and judgements refined. Feedback on such discrepancies is probably more important than feedback on any other matter, because if a misperception of judgement occurs then the learner may not know that they need to take any useful action to remedy their work and perform better subsequently.

There is an inherent tension however in providing guidance to students on their own judgements to help improve them, and students becoming more able to exercise evaluative judgement independently of teachers. Providing information to students to assist them calibrate their judgement is only one part of a more complex process of them developing their own expertise. Students need also to learn when not to trust the judgements of others.

\section{Grade judgements}

One measure of students' ability to judge their own work is the grades they give to assignments. A student who is a good judge of their own work is likely to rate their work in a similar way to an experienced judge of the same assignment, assuming they share the same criteria for assessment. These experienced judges should be viewed with caution however, as research on the reliability of tutor marking over the past 85 years or so (since Hartog and Rhodes, 1935, 1936) would suggest that there can be considerable error and inconsistencies in tutor judgements and also variation across tutors, depending on the nature of the task assessed. Notwithstanding this, the most readily available surrogate for an expert judge is the person who marks assignments and allocates grades. While over many assignments this person changes, and their marks are subject to normal variation, without the intrusion of other measures, this, with the moderation processes that take 
place, is as close as one can get to expert judgement in a normal teaching environment. It should also be noted that there might be a difference between measurement (that is marks) and judgement (what is acceptable or not). Yorke (2007) discusses that when judgement is used rather than measurement then marker reliability is far higher.

There have been considerable studies over a long period of time comparing students' marks with those of teachers (Boud \& Falchikov, 1989; Falchikov \& Boud, 1989, Dochy, Segers and Sluijsmans 1999). These and subsequent studies show that students are reasonable judges of their own grades, but that the accuracy of judgement varies according to the expertise of the student and the level of course: stronger students are more likely to underestimate grades, weaker students overestimate; students in advanced courses are more likely to underestimate, students in introductory courses overestimate. It follows from this that it would not be surprising to find a tendency that when students encounter new subjects or academic areas, their ability to make good judgements of their work declines.

There are many limitations of such studies as Ward et al (2002) have pointed out. Not least of these is reliance on experienced raters of performance as the gold standard in selfassessment. They suggest the need for multiple experienced raters, better use of scales and using an intra-individual, as opposed to inter-individual, comparison process, that is, comparing individuals with their own performances over time. They warn though that, 'studies that make use of the traditional designs to study self-assessment without accounting for the potential methodological flaws inherent in these approaches will not be able to contribute meaningfully to the self-assessment literature in the future.' (Ward et al 2002, p.80)

\section{The study}

Our study involved the tracking of assessments students made of their own work against that of the marker across assignments in an undergraduate design program in an Australian university. The assessments were facilitated by a criteria-based assessment system (ReView). The degree program used the web-based system to publish criteria that referred to the specifics of each task rather than 'fixed sets of criteria' (Sadler, 2009, p.159). These criteria make explicit the aspects of learning valued in the assessment of the subject taught. Instead of usual grade codes (F, P, C, D, HD) being used in benchmarking with tutors and discussions with students, the more descriptive terms Passable, Creditable, Distinctive and Highly Distinctive were used. These terms were intended to replace the usual reference to percentage marks to encourage the development of a judgement culture (Sadler, 2005 p.190).

The completion of student self-assessment revealed visually the variation between their own grading and the tutor's grading for each criterion. During the period of the study students engaged in voluntary self-assessment and graded their work on a sliding scale 
against criteria prior to the tutors entering their grading into the web-based system. Whilst the percentage marks were not shown to students in their ReView feedback these were recorded in the database and have been used as the data for statistical comparison in this study.

\section{Data used}

Students were enrolled in a four-year undergraduate design program, the Bachelor of Design (Honours). The degree has four discipline strands, Industrial Design, Visual Communication Design, Fashion and Textile Design and Interior Design with a total of approximately 1400 students.

The data used in the study was students' individual self-assessment grades for up to four tasks in each subject taken per semester. Each of the tasks had descriptive criteria against which percentage marks were gathered as well as the total percentage mark for each task. Tutors' judgements of student performance were gathered for comparison with students' self-assessments, which the system also stored as percentage marks. Each subject was taught by varying numbers of tutors according to subject size, but in this study between one and six. In the Design program there has been a tradition of moderation across tutors to reduce inter-tutor variation.

The ReView software is a web-based marking aid developed by Darrall Thompson, an academic in the Visual Communication Design program. Due to the convenience of online marking and improved efficiencies in the management of tutors, the system usage in the design degree program has gradually increased during the period from which data was collected from 56 subjects (units of study or course modules) in 2008 to 127 subjects in 2010. However, this increase has largely been through word of mouth with no official training or guidance for academics, although approximately twenty per cent were personally supported in the use of the system or attended demonstrations of the software.

ReView was designed to give criteria-based feedback and comments. It provides various options that can be enabled (including self-assessment). Students can track their progress over time through a visual representation of grades by category of criteria. The student self-assessment option was available to academic staff when setting up their tasks or assignments for marking, but unless staff attended one of the demonstrations mentioned they would be unaware of the option and its educational value. The data used in this study is from academic subjects that had this feature enabled during the data collection period. These included:

13 in Industrial Design

7 in Multidisciplinary Research

10 in Interior Design

20 in Visual Communication Design 
These subjects had between a minimum of two and a maximum of four summative assessment tasks for students to complete.

The tutors in these subjects were professional practising designers and the subject coordinators were full time or fractional academics with professional design experience. The study data is drawn from a broad range of assessment tasks, they included:

- Individual and group projects, research reports and oral presentations,

- Critical and reflective essays,

- Portfolio presentations of individual exhibitions of work.

There are no examinations used in the design degree.

The assessment criteria for these tasks varied in clarity and level of specificity. Subject coordinators classified them into groupings of graduate attributes and edited them to be relevant to the task.

To illustrate what students might see, the following criteria are from one Industrial Design task weighted at $50 \%$ of the total assessment in the subject:

1. Professional approach to the explanation of consumer benefits and other factors affecting the appropriateness of solutions.

2. Appropriate use of convergence tools, eg. linkograph, taught in this subject.

3. Depth of consideration regarding the evaluation and validation of your proposal.

4. Level of innovation and or creativity evident in your proposal.

5. Quality of synthesis of ideas generated through creative thinking processes.

6. Appropriate outcome based on the context outlined in your restated brief.

Another example is from an Interim Presentation task in the Visual Communication Major Project subject, weighted at $30 \%$.

1. Level of innovation and appropriateness of design response to findings drawn from archive

2. Clarity of project presentation communicated by the design of the three A3 panels

3. Quality of understanding of positioning of designed response in relation to viewer engagement/ response and potential social implications (including ethical considerations where appropriate.

4. Quality of presentations to audience of peers, tutors and Industry Advisor.

5. Appropriateness of project proposition evidenced in the research underpinning the project

6. Depth and range of visual (contextual, experiential and/or generative) investigation undertaken

7. Clarity and relevance of insights/significant findings drawn from the archive 
There was a visual grading scale next to the criterion that corresponded to the following bands:

$$
\begin{array}{ll}
0-49 \% & \text { F (Fail) } \\
50-64 \% & \text { P (Passable) } \\
65-74 \% & \text { C (Creditable) } \\
75-84 \% & \text { D (Distinctive) } \\
85-100 \% & \text { HD (Highly Distinctive) }
\end{array}
$$

The process of tutors entering ratings against criteria happens through the use of visual 'data sliders' as shown in Figure 1.

Insert Figure 1 here

Once the staff member has completed marking for a student's work and clicked 'Save', if the student has self-assessed, blue triangle sliders appear. This immediately flags to the marker that there were sometimes disparities between their marks and the students grading judgements. Some staff used this disparity to subsequently guide comments to students typed into a comment box. This allows for feedback to focus on areas where students have a lack of accurate perception of their performance on a criterion and is therefore part of their work that needs extra feedback. There is also a moderation mechanism within the system where subject coordinators can benchmark marking across the teaching team.

Students use a similar interface to enter their self-assessment ratings of their own work. After the Subject Coordinator publishes the tutors' marking, students can see their selfassessment triangles compared to the tutors' assessments. In the student interface, percentage numbers are not displayed and the tutors' black grading bar was spread (as can be seen in Fig 2) in order to reduce the focus on marks and foreground the pattern of feedback against criteria. It should be noted that ReView is not the official repository for marks and does not replace the record-keeping system administered by the university.

Insert Figure 2 here

Motivation to engage in self-assessment

No student in this study was required to self-assess against the criteria or rewarded for 
doing so. There are a number of reasons why students may have decided to engage in self-assessment. The novelty factor or encouragement from a keen academic tutor may have encouraged initial participation, but the students in this study self assessed over at least two semesters. So perhaps they were using self-assessment as a way of understanding the criteria used for assessing a task or developing a value for the visual comparison between their own estimates and teachers' grades. Given the potential educational benefits of this reflective process, investigating how to improve the intrinsic motivational factors could be an interesting further study. Missing data arises both from those subjects in which coordinators had not enabled the self-assessment features, and from students who chose not to avail themselves of the facility when it was enabled.

\section{Response Rates}

This research was not conceived until after this assessment system (ReView) had been used for several years by academics teaching in the degree. Given that the use of ReView was voluntary, we selected to use data from students who had used ReView to self-assess over a minimum of two semesters. This meant that even though we had self assessment scores matched with tutors' marks for over 13,000 criteria we only used 2196 self assessments from 182 students. As the study was focusing on the effects of selfassessment over time we also conducted analyses on students who had used ReView over three semesters (66 students), and four semesters (24 students). The data for students completing more than four semesters of self-analysis was limited and so has not been included in this study. It should also be noted that numbers for third and fourth tasks is reduced, as a number of subjects required only two summative assessments tasks within their subject.

The data is clearly limited and the results of the analysis reported here are merely suggestive. We do not know what the effects would be of including students who chose not to undertake the exercise. We suspect that as the missing students are more likely to be the less conscientious and perhaps the less able, the effects may be weaker than we identify here. The act of expecting students to undertake self-assessments though is not predictable. It may be that a formal requirement could act as a scaffolding effect to support the very students who need most assistance in developing their judgement. However, unless students enter into the process with serious and committed intent, then any intervention is likely to be ineffective.

\section{Questions addressed}

The data available enabled us to address the following questions:

1. Do students' marks agree with tutors' within a subject?

2. Do differences between tutors and students decrease with each subject undertaken? 
3. Does students' overall performance affect their ability to agree with tutor marks?

4. Does students' ability to calibrate lead to improved performance?

1. Do students' marks agree with tutors' within a subject?

Insert Figure 3 here

A series of paired t tests were conducted on overall differences between tutor and students scores on tasks within a single subject. There was a significant difference found between the student and the tutor at the first task, with students rating themselves higher than the tutors $(\mathrm{t}(1,2827)=9.279 ; \mathrm{p}<0.00)$. By the second task this significant difference was no longer evident $(\mathrm{t}(1,1347)=-0.654 ; \mathrm{p}=0.513)$, and remained non significant for third $(\mathrm{t}(1,553)=-0.068 ; \mathrm{p}=0.945)$ and fourth $(\mathrm{t}(1,102)=-1.482 ; \mathrm{p}=0.141)$ tasks where present.

This suggests that although students may initially struggle to accurately self assess, with time and benchmark scores from their tutor they appear to get more accurate. However, the data shows greater divergence on the fourth task, but the sample size for this is diminished. It should be noted that while most subjects had three assessment tasks per semester, some had four, so in Figure 3, the third task is the final task for the semester for the majority.

\section{Do differences between tutors and students decrease with each subject undertaken?}

Insert Figure 4 here

A series of paired t tests was undertaken to examine if the difference between students and tutors marks at task 1 decreased with practice over semesters. It was found that students were significantly higher than tutors in the first task of their initial three semesters of self-assessing (Semester $1(\mathrm{t}(1,909)=8.259 ; \mathrm{p}<0.00)$; Semester $2(\mathrm{t}(1$, $1170)=3.878 ; \mathrm{p}<0.00)$; Semester $3(\mathrm{t}(1,435)=3.365 ; \mathrm{p}<0.01))$. By the fourth semester there was no significant difference between students and tutors $(t(1,216)=1.956$; $\mathrm{p}>0.05)$.

This suggests that for the first task in a new subject, students appear to refine their judgement over time. There is convergence between student and tutor marks for each first 
task. However, the sample size for semester 4 is considerably lower than for the other semesters. When the effect size for semester 4 is considered in light of this smaller sample size it is found to be 0.05 which indicates a large overlap between the tutor and student marks and so reinforces the t test finding.

\section{Does students' overall performance affect their ability to agree with tutor marks}

Insert Figure 5 here

In order to investigate differences between students with differing achievement levels the sample was divided into three achievement level groups, low, mid and high. This was derived from the tutors' marks on completion of the assignments. The low achievement group consisted of students who scored less than $60 \%$ in their tasks, the high achievement group was students who were marked at higher than $75 \%$ and the mid group were the students who fell between these two percentages. When students were examined according to their achievement level, it was found that the low achievement students significantly over estimated their performance at both the first $(\mathrm{t}(1,249)=22.461 ; \mathrm{p}<0.00)$ and last $(\mathrm{t}(1,81)=12.724 ; \mathrm{p}<0.00)$ examples of assessments. The high achievers significantly underestimated their performance at the initial $(\mathrm{t}(1,778)=-15.398 ; \mathrm{p}<0.00)$ and final $(t(1,173)=-8.297 ; \mathrm{p}<0.00)$ stages of assessment. The mid group however were significantly higher than the tutors at the beginning task $(\mathrm{t}(1,1698)=13.427 ; \mathrm{p}<0.00)$ but by the end task there was no significant difference between themselves and the tutors $(\mathrm{t}(1$, $65)=1.466 ; \mathrm{p}=0.148)$.

This suggests that it is the mid achievement group who were the most able of the three groups in developing self-assessment skills in this context.

\section{Does students' ability to calibrate lead to improved performance?}

Insert Figure 6 here

The students were categorized as being over estimators, under estimators or accurate estimators in order to address this final question. The groups were divided by calculating the difference between the student and tutor mark on each task on completion of the assessments. Those students who were within three per cent (above or below) of the tutor's score were deemed to be accurate estimators, whereas students who were more 
than three per cent below the tutor were classed as under estimators and those more than three per cent above the tutor's mark were assigned as over estimators. A one-way ANOVA was conducted to look at differences in performance scores in relation to ability to calibrate, i.e. over estimators, under estimators and accurate estimators. In the first semester the over estimators showed significant higher scores on each subsequent task compared to the first $(\mathrm{F}(3,606)=12.607 ; \mathrm{p}<0.00)$. Again, in the first semester the under estimators showed a significantly higher score in the second task than the first task $(\mathrm{F}(3,463)=3.489 ; \mathrm{p}<0.05)$ but did not show any significant differences in following tasks or semesters. The accurate estimators however showed a significant increase in scores across all the tasks in the first semester $(\mathrm{F}(3,700)=10.099 ; \mathrm{p}<0.00)$, and the second $(\mathrm{F}(3,688)=6.171 ; \mathrm{p}<0.00)$ and third $(\mathrm{F}(3,222)=5.064 ; \mathrm{p}<0.01)$ semesters.

This data suggests that students who are both accurate estimators (mid-range achievers) and to a degree those who tend to underestimate their performance (high achievers), improve their performance over successive tasks. However, over-estimators, who tend to be poor achievers, do not appear to learn how to improve their performance over time.

\section{Discussion}

The finding (Figure 3) that students' self-assessment marks converge with tutors over the length of a semester is not unexpected and supports previous work on self-assessment (Lawson et al, 2012; Lew, Alwis and Schmidt 2010). It is however encouraging to note that, within a subject, students' understanding of the criteria and standards expected in that particular subject develops.

Figure 4 tells a more detailed story, indicating that although within a subject, students' ability to accurately self-assess increases when they begin a new subject, the difference between self-assessment mark and tutor mark is again evident. This may be due to having to understand a new set of criteria and standards for each subject and so would suggest that this increase in accurate self-assessment is not immediately transferrable. It was not until students had experienced three semesters of self-assessment that they showed the ability to adapt to a new subject and more accurately self assess from the first task. It should be noted that completing three semesters involves a change in academic year for the student and so the potential for facing higher standards, for example the difference from first year to second year.

The breakdown of students into groupings of high, mid and low achievement reveals quite strong contrasts between the groups. The data in Figure 5 confirms the findings from many other studies of self-assessment (Falchikov and Boud 1989) that high achievers tend to underestimate performance and low achievers over-estimate performance. However, Figure 6 provides some intriguing hints about more detailed 
differences in these groups. The accurate estimators tend to increase their performance as the semester progresses on each task, with the under estimators also showing some improvement in performance, but the over estimators do not show any progress in performance over time. It may be that this group is content to merely pass each task and has no desire to invest the effort to do better, or they may not have the capability to improve without additional educational interventions. This study does not provide an explanation of why this might occur.

\section{Implications}

While this is an initial study with the various limitations noted, it does suggest that students can become better judges both within a subject and across a range of subjects over time. However, when confronted with new subject matter, their judgment declines somewhat, suggesting that the ability to make judgements may be domain-specific. Judgement improves again with further application in more subjects. This provides some support for a practice effect.

The study gives support to the idea that students can improve their grades and become more effective judges of their own work through self-assessment practice, ie. with knowledge of standards and comparison of standards to their own work and 'direct and authentic evaluative experience' (Sadler, 1989). But it does so only with students who volunteer to undertake the process and we have no knowledge of the extent of particular action taken by students to close the gap between standards and their own work (Sadler, 1989). The study also suggests that there may be a regression effect in that when students are confronted with a new subject, there is a tendency for them initially to be less effective in judging their performance than in a subject with which they have had prior practice. There is also a suggestion that students become more effective in criteria-based judgement over semesters.

Improvement in ability to make judgements is of interest. If the improvement were due to the repetition of being given the opportunity to self-assess then one would expect judgements to continually improve over time over all units of study. This was not the case. It would therefore suggest that this improvement within a subject would be due to students gaining a better understanding of the expectations of the assignments. This may be through the experience of completing the work or by receiving feedback on it from the experienced marker. The improvement in judgement over time, would suggest that students also have to learn to adapt their understanding of these expectations to each new unit of study, a skill not mastered automatically.

In order to explore this further a fuller data set that includes a greater sample of students over a longer timescale would be necessary. A full population of students rather than just 
volunteers would also be desirable. Further studies need to be considered in other disciplines as our findings may arise as an effect of courses in Design or of assessment types used in the courses studied. It would also be valuable to consider groups of course modules in which one builds on another to see if the apparent learning effect is greater within particular subject matter. Of greater importance would be studies that examined whether students who improved their self-assessment accuracy increased their grades vis $a$ vis other students. If there were greater security of findings, there would be important implications for the design and structure of courses and the involvement of students in assessment decisions. More deliberate interventions might have a greater impact than the rather passive measures explored in this study. Strategies that might be considered are the provision of detailed feedback information from tutors on the quality of students' selfassessments, and the engagement of students in exercises working with standards and criteria to appreciate how they can apply them to their own work. In the present study, the assumed motivational effects of having tutors' marks and feedback revealed immediately on completion of the self-assessment task meant that tutors could not have knowledge of student ratings before writing their initial comments. If tutors could provide information to help students' focus their judgements this might have greater impact on the development of self-assessment over time. Such a strategy if undertaken after the initial set of tutor comments would open up possibilities for the kinds of dialogic feedback proposed in recent publications (eg. Carless et al, 2011, Boud and Molloy, 2012).

\section{Conclusion}

Notwithstanding that this is an initial study with incomplete data biased towards students enthusiastic in seeking to judge their own performance, there are interesting pointers to phenomena that if confirmed would have quite substantial pedagogic implications. The study addressed the question of whether student engagement in self-assessment over an extended period of time in a standards-based context could help calibrate their judgement and make them more effective judges of their own work. The tutor data and the student self-assessments show no significant differences by the second assessment task in a unit of study which suggest that students' judgements converge with those of tutors. It was also found that this convergence was not evident when students began a new unit of study and that this more accurate judgement did not occur in an initial task in a new unit until students had had opportunities to practice self-assessment over three semesters.

This outcome is potentially important as it supports the notion that under appropriate conditions most students can improve their judgement skills. However, when students are categorised by achievement level, differences are found in students' ability to develop accurate judgement. High achievers are found to under-estimate their ability whilst low achievers over-estimated. When the groupings were examined for performance over time, it was the accurate estimators (the mid achieving group) showing the highest level of 
improvement, with the under-estimators (high achievers) demonstrating some increased performance, but improvements were not evident in under-achievers. This has important implications for both educators and learners in appreciating the role of criteria and standards in assessment and how understanding these elements needs to be fostered to develop students' judgement in order to support optimum performance.

Further research needs to be undertaken to explore the improvement in judgement skills in other settings. Such studies could usefully address conditions that more actively promote the development of self-assessment skills, and the kinds of intervention needed for lower-achieving students to show similar improvements to the majority of their cohort.

\section{References}

Boud, D. (1995) Enhancing Learning through Self Assessment. London, Routledge.

Boud, D. (2000) Sustainable assessment: rethinking assessment for the learning society. Studies in Continuing Education, 22 (2), 151-167.

Boud, D. \& Falchikov, N. (1989) Quantitative studies of student self assessment in higher education: a critical analysis of findings. Higher Education, 18, 529-549.

Boud, D. \& Falchikov, N. (2007). Developing assessment for informing judgement. In Boud, D. \& Falchikov, N. (Eds.) (2007). Rethinking Assessment for Higher Education: Learning for the Longer Term. London: Routledge, 181-197.

Boud, D. and Molloy, E. (2012). Rethinking models of feedback for learning: the challenge of designAssessment and Evaluation in Higher Education, DOI: 10.1080/02602938.2012.691462

Black, P. and Wiliam, D. (1998) Assessment and classroom learning. Assessment in Education, 5, 7-74.

Carless, D., Salter, D., Yang, M. and Lam, J. (2011) Developing sustainable feedback practices', Studies in Higher Education, 36, 5, 395-407.

Dochy, F., Segers, M. \& Sluijsmans, D. M. A. (1999). The use of self-, peer and coassessment in higher education: A review. Studies in Educational Evaluation, 24, 3: 331-50.

Dreyfus, H. L. \& Dreyfus, S. E. (2005) Expertise in real world contexts. Organization Studies. 26, 5, 779-792.

Ericsson, K. A., Krampe, R. T. \& Tesch-Romer, C. (1993). The role of deliberate practice in the acquisition of expert performance. Psychological Review. 100. 3, 363-406

Falchikov, N. \& Boud, D. (1989) Student self assessment in higher education: a metaanalysis. Review of Educational Research, 59 (4), 395-430.

Galbraith, R M, Hawkins, R E \& Holmboe, E S. (2008). Making self-assessment more effective. Journal of Continuing Education in the Health Professions. 28(1), 20-24.

Hartog, P. \& Rhodes, E.C. (1935). An Examination of Examinations. London: Macmillan.

Hartog, P. \& Rhodes, E.C. (1936). The Marks of Examiners. London: Macmillan.

Lawson, R., Taylor, T., Thompson, D., Simpson, L., Freeman, M., Treleaven, L. Rohde, F. (2012). Engaging with Graduate Attributes through Encouraging Accurate 
Student Self-Assessment. Asian Social Science, 8 (4). 3-12.

Lew. M D N, Alwis W A M, \& Schmidt, H G. (2010). Accuracy of students' selfassessment and their beliefs about its utility. Assessment \& Evaluation in Higher Education. 35, 2, 135-156.

Nicol, D (2009), Assessment for learner self-regulation: Enhancing achievement in the first year using learning technologies. Assessment and Evaluation in Higher Education. 34, 3, 335-352.

Nicol, D. (2010). From monologue to dialogue: Improving written feedback in mass higher education. Assessment and Evaluation in Higher Education, 35(5), 501517.

Nicol, D.J. \& Macfarlane-Dick, D. (2006). Formative assessment and self-regulated learning: A model and seven principles of good feedback practice. Studies in Higher Education. 31, 2, 199-218.

O’Donovan, B., Price, M. \& Rust, C. (2008) 'Developing student understanding of assessment standards: a nested hierarchy of approaches', Teaching in Higher Education, 13 (2), 205-217

Ramaprasad, A. (1983). On the definition of feedback. Behavioral Science, 28, 4-13.

Sadler, D. R. (1989). Formative assessment and the design of instructional systems. Instructional Science. 18, 119-144.

Sadler, D. R. (1998). Formative assessment: revisiting the territory. Assessment in Education, 5, 1, 77-84.

Sadler, D. R. (2005). Interpretations of criteria-based assessment and grading in higher education. Assessment and Evaluation in Higher Education, 30, 175-194.

Sadler, D. R. (2009). Indeterminacy in the use of preset criteria for assessment and grading in higher education. Assessment and Evaluation in Higher Education, 34, 159-179.

Ward, M., Gruppen, L. \& Regehr, G. (2002). Measuring self-assessment: current state of the art. Advances in Health Sciences Education, 7, 63-80.

Yorke, M. (2007). Grading Student Achievement in Higher Education: Signals and Shortcomings. London: Routledge. 


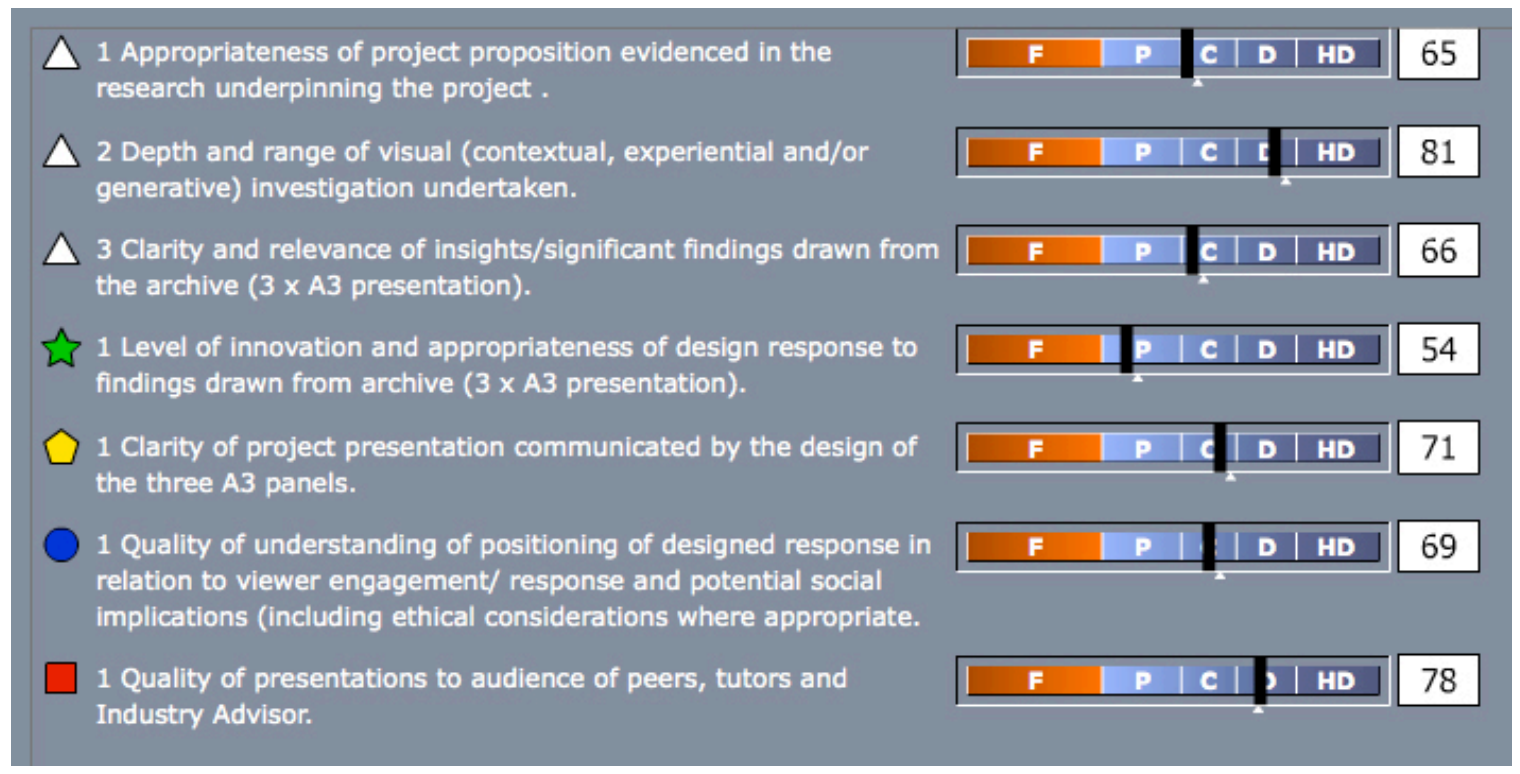

Figure 1. Screenshot from the ReView software showing data sliders for tutors marking against criteria. As the black bar is dragged the percentage numbers appear alongside the slider. 


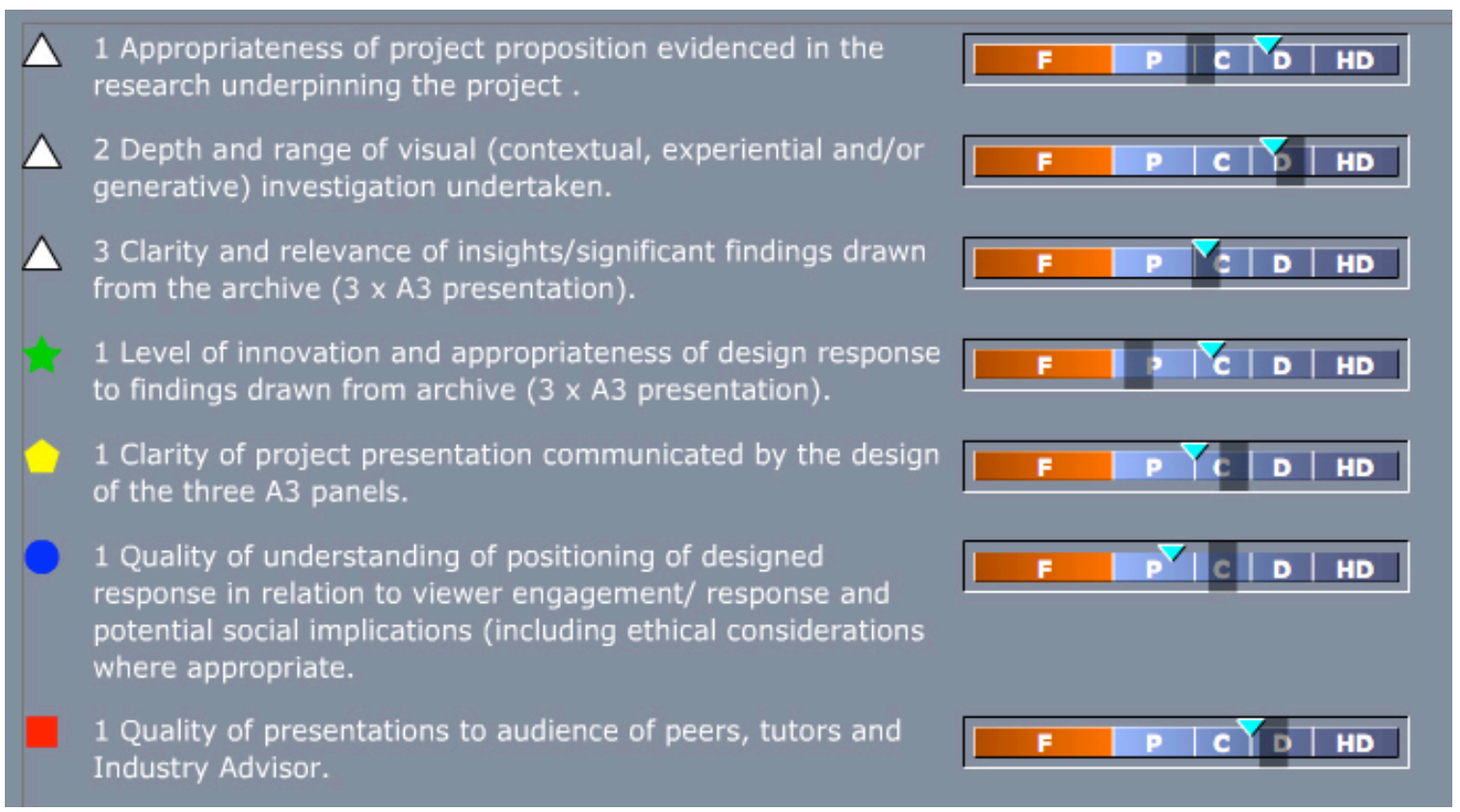

Figure 2. Screenshot of students interface showing the tutor's assessment (grey bars) in relation to their own self assessments (triangles) 


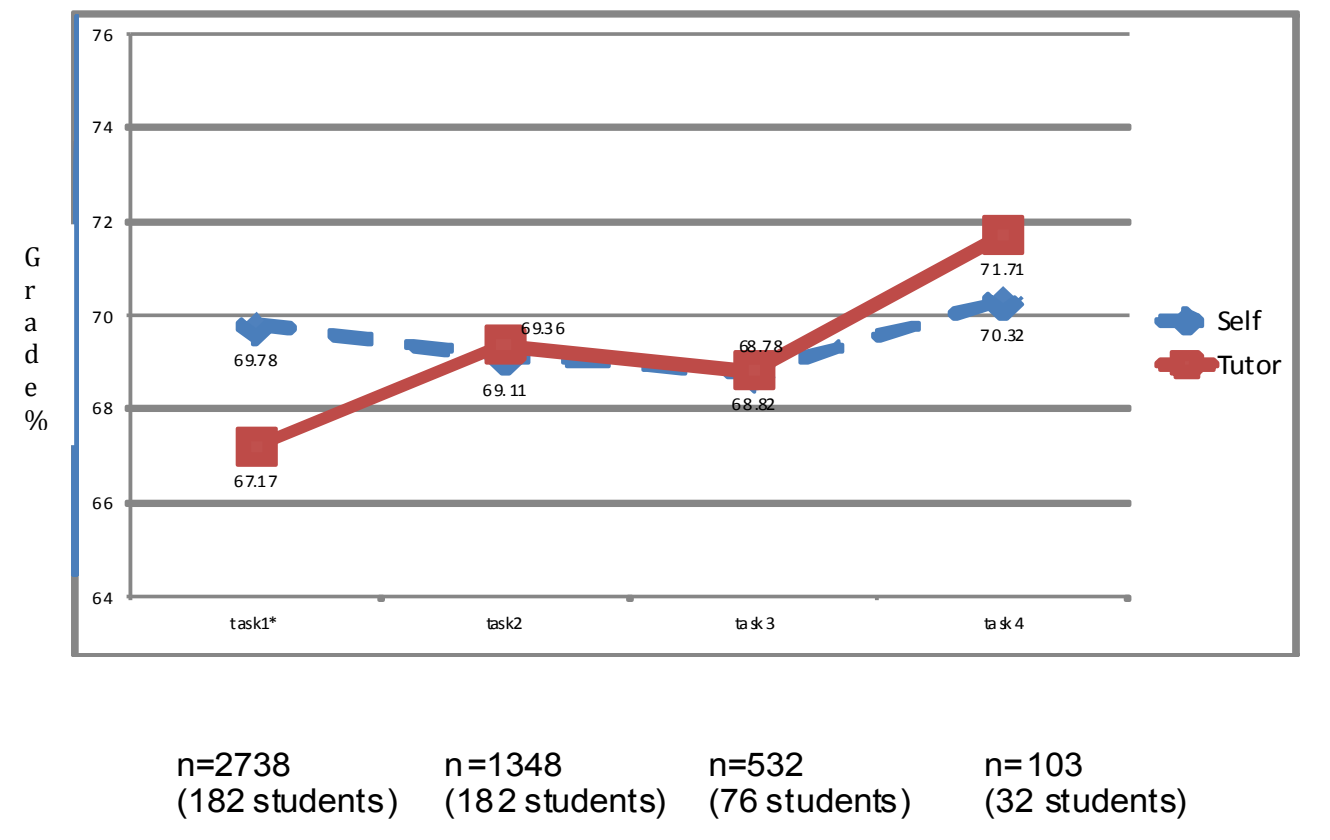

Figure 3. Comparison of tutor and student scores on assessment tasks within a subject 


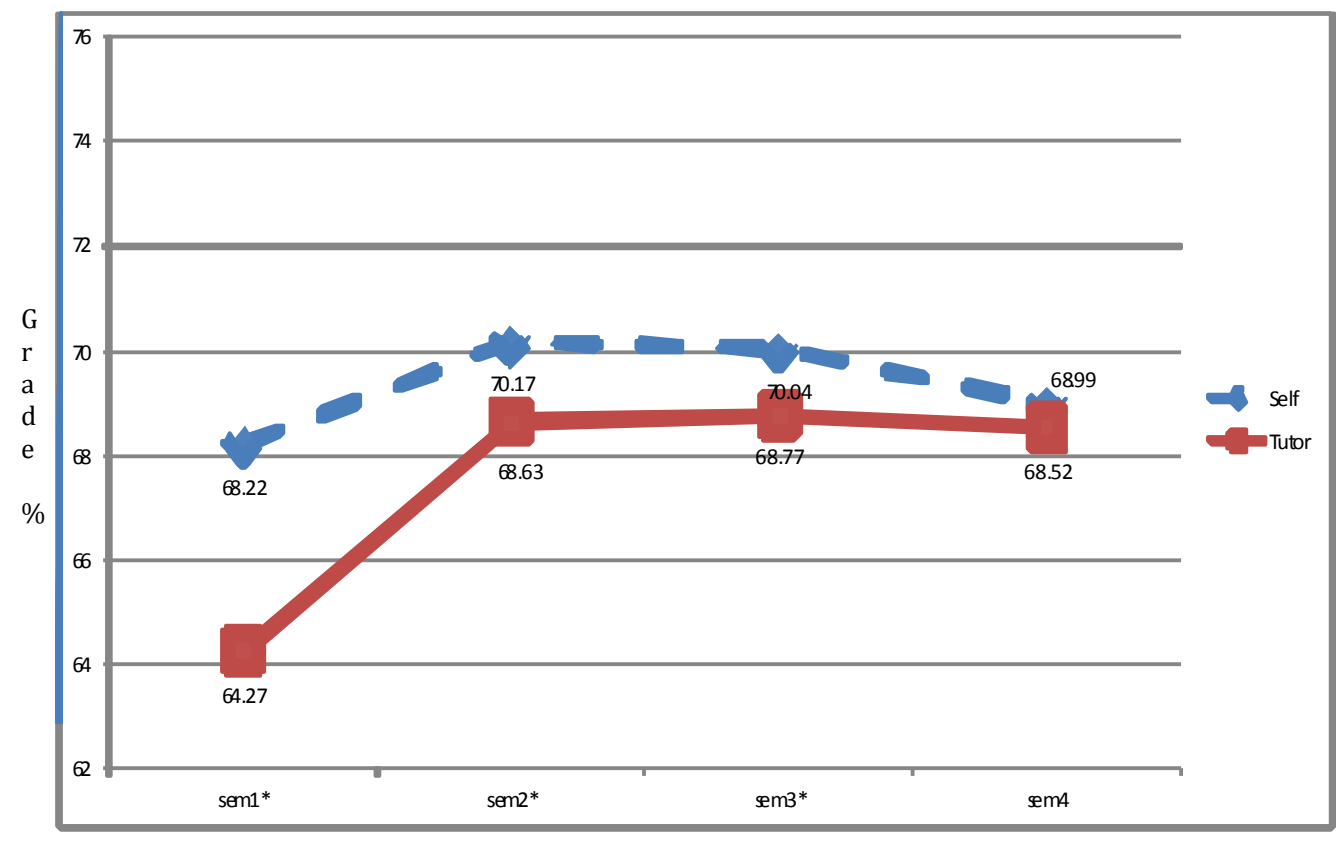
$\mathrm{n}=910$
$\mathrm{n}=1171$
$\mathrm{n}=436$
$\mathrm{n}=217$
(182 students)
(182 students) (66 students)
(24 students)

Figure 4. Differences between student and tutor marks on the first task in each subject over four semesters. 


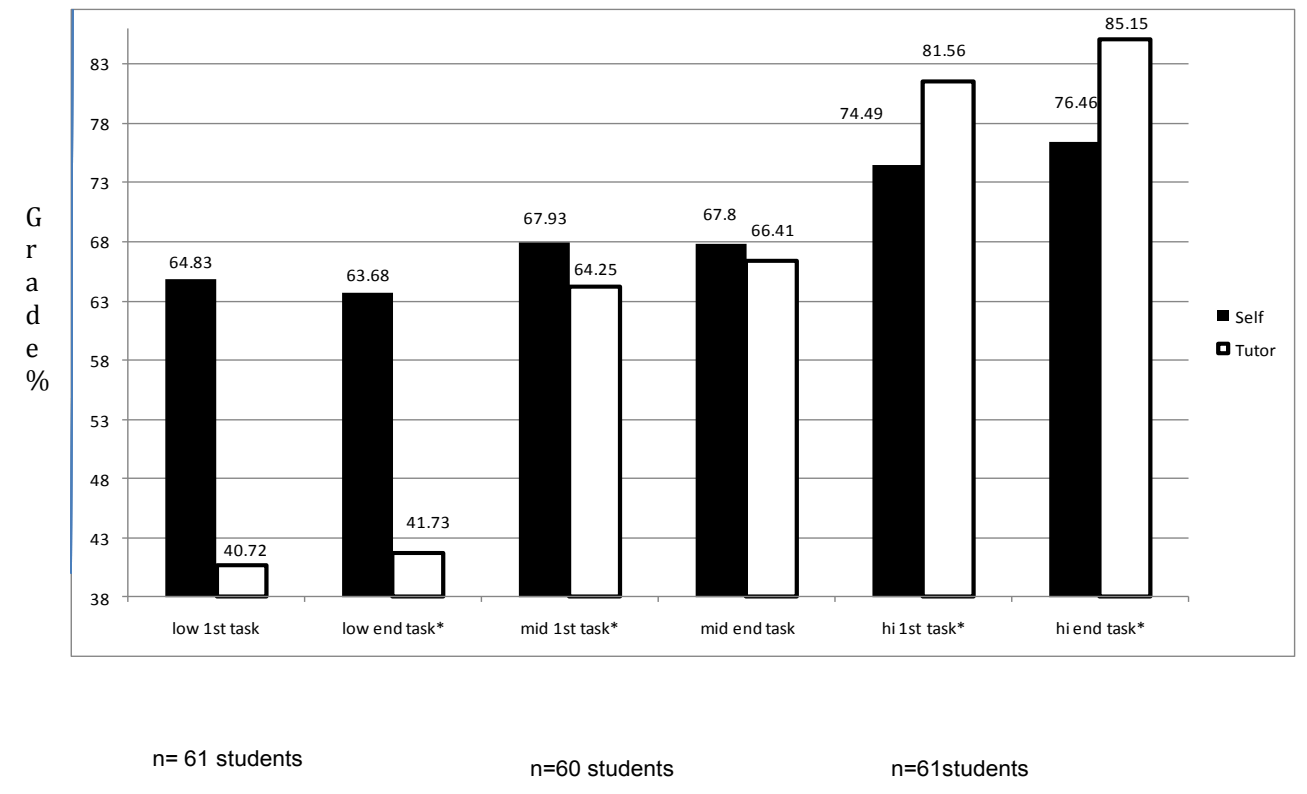

Figure 5. Comparisons between first and last assessment tasks in a given semester by student achievement level. 


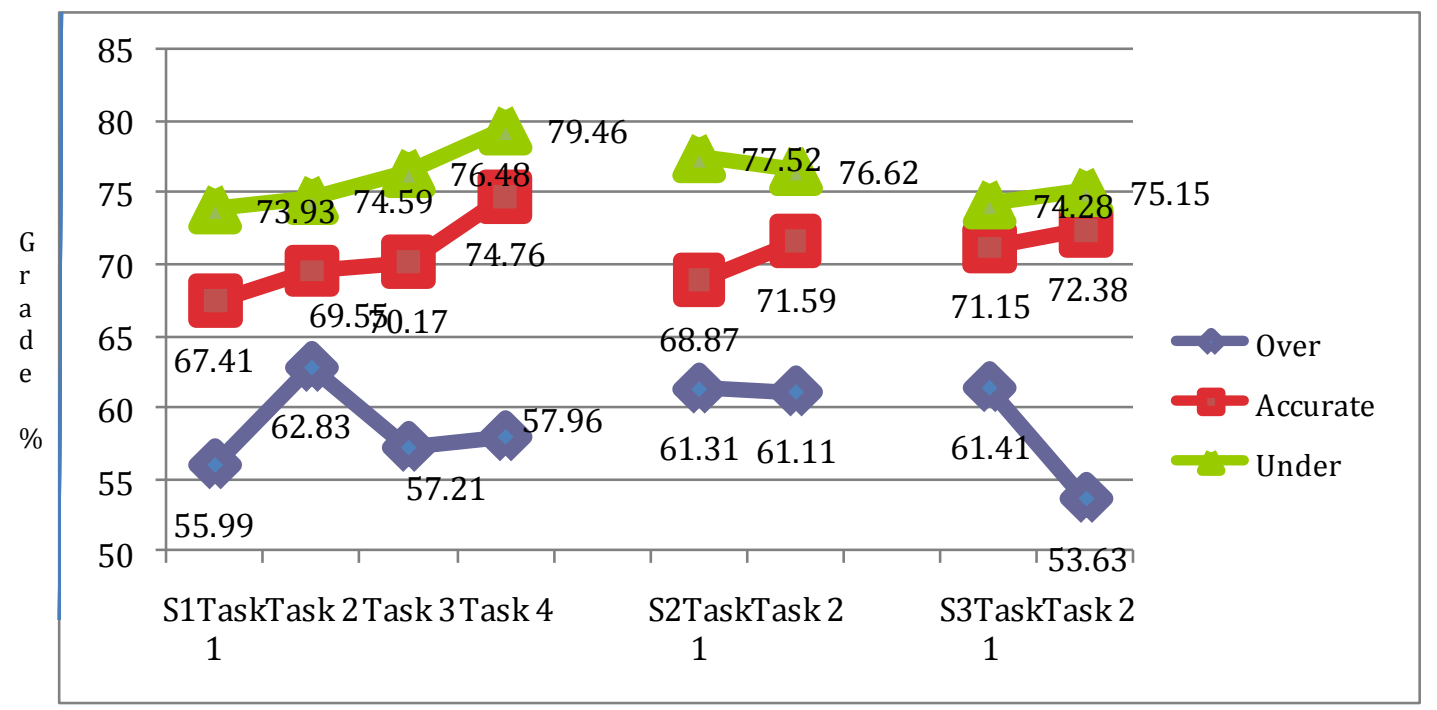

Figure 6. Difference in performance scores by ability in calibrating judgement. 